\title{
Resposta de inversão de dados Sintéticos 1D do método da Sondagem Elétrico Vertical ao sistema aquífero poroso no município de Santarém e Alter do Chão.
}

\author{
Aquino,M.P.*1 , UFOPA;Tejada, S. Z. R. ${ }^{2}$,UNSA; Piedade,A.A. ${ }^{3}$, UFOPA; Fernandes, S.C. ${ }^{4}$,UFOPA
}

\section{Resumo}

A inversão de dados geoelétricos aplicada neste trabalho, é o método de Sondagem Elétrica Vertical (SEV), com intuito de comparar dois tipos de arranjos, Wenner e Schlumberger, em três situações distintas, em épocas de estiagem, recarga máxima e sujeitas a contaminantes, sejam estes orgânicos ou inorgânicos. A resposta de inversão apresentada, visa mapear o aquífero sedimentar ante as diferentes situações mencionadas, utilizando dados sintéticos preparados a partir de informações reais disponibilizados no site da Companhia de Recursos Minerais (CPRM), os dois poços modelados computacionalmente encontram-se localizados no município de Santarém e na vila de Alter do Chão. Finalmente os resultados obtidos permitiram avaliar e analizar as caraterísticas do aquífero para ambos os locais, identificando o poço mais suceptível a contaminação. Desta forma permitiu-se elaborar o perfil geoelétrico.

\section{Introdução}

Alter do Chão, é considerado um dos reservatórios de água favoráveis para o consumo humano. No entanto, se desconhece a quantidade de poluente que possui, isto por falta de gestão urbana. O aquífero é conhecido atualmente como o sistema aquífero grande Amazônia (SAGA), com uma extensão de $162.520 \mathrm{~km}^{3}$, que comprendem as bacias sedimentares do Acre, Solimões, Amazonas e Marajó, tendo profundidade do aquífero confinado de até 500-600 $m$ (ABREU (2013)).

Portanto, tem-se por objetivo localizar por meio da modelagem computacional utilizando o método da SEV o aquífero poroso superficial, analizado em épocas de recarga máxima e estiagem, assim como o perfil mais suscetível a contaminantes orgânicos e/ou inorgânicos. Dessa forma, pode-se realizar uma correlação da modelagem direta de dois poços disponibilizados pela CPRM e com intuito de comparar os resultados obtidos em relação aos dois tipos de arranjos eletródicos diferentes: Wenner e Schlumberger.

A metodologia abordada, mostra resultados favoráveis com a distribuição dos arranjos Schlumberger, para ambos os poços, obtendo os perfis geoelétricos, logo as resistividades aparentes obtidas na inversão variaram conforme os períodos citados acima.

\section{Metodologia}

\section{Teoria do método Sondagem Elétrica Vertical}

A SEV vem a ser usada para investigações verticais pontuais, empregadas para estudar a estratifição horizontal dos interfaces. Teoricamente na sua interpretação de um parâmetro físico obtido através de medidas efetuadas na superfície do terreno. O presente método nos permite medir a resistividade aparente do subsolo, cujos valores dependem das valores verdadeiros das rochas presentes em sub-superfície (Orellana (1972)). Essa propriedade para um dado arranjo, do quadripolo AMNB é obtida a partir dos parâmetros:

$$
\rho_{a}=K \frac{\Delta V}{I}
$$

onde $K$, é determinado pela distância entre os eletrodos do dispositivo e é denominado como fator geométrico ou coeficiente do dispositivo.

Para o arranjo Wenner o fator geométrico é dado pela equação:

$$
K=2 \pi a
$$

e para o arranjo Schlumberger o fator geométrico é expressado pela seguinte equação :

$$
K=\frac{2 \pi L^{2}}{a}
$$

Para os arranjos lineares são colocados quatro eletrodos na superfície do terreno, dispostos simetricamente em relação ao centro e sobre a mesma reta. Nesse estudo, vamos descrever os tipos de arranjos, conforme ilustrado na figura 1 adaptado de Braga (2016). No Schlumberger, os eletrodos de potencial permanecem fixos com sua relação de $\mathrm{MN}=\mathrm{a}$ e $2 \mathrm{~L}=\mathrm{AB}$. No Wenner tem sua relação de $\mathrm{AM}=\mathrm{NM}=\mathrm{NB}=\mathrm{a}$, sendo $O$ o centro do arranjo. (a) Schlumberger

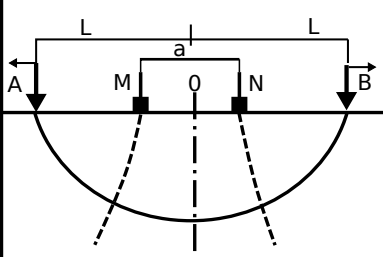

a: Fixo

L: Crescente (b) Wenner

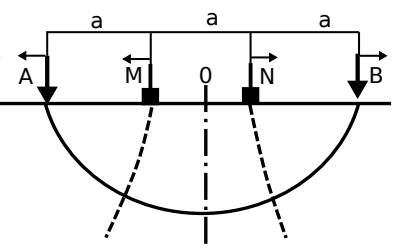

a: Crescente
Figura 1: Ilustração adaptada da obra de Braga (2016) dos arranjos a) Schlumberger e b) Wenner.

\section{Área de Estudo}

Utilizamos para esse trabalho, dois dados litológicos de poços, dispostos pelo site da CPRM, situadas na Pousada do Mingote no balnéario de Alter do Chão, e no Shopping Center Tapajós encontrado na cidade de Santarém, no estado do Pará, na região norte do Brasil, conforme a 
figura 2. Esses poços pertencem a aquífero grande Amazônia, para ter uma ideia do tamanho gigantesco que tem, o aquífero Guarani, foi considerado o maior do mundo antes da descoberta do SAGA, que possui $39 \mathrm{mil} \mathrm{km}^{3}$. Ou seja, atualmente, é mais de quatro vezes menor que o SAGA.

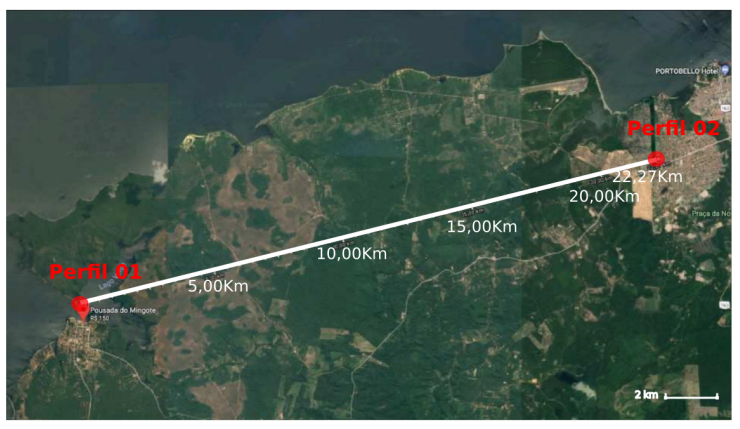

Figura 2: Mapa obtido do Google Maps referentes ao objeto de estudo: Pousada do Mingote e no Shopping Center.

Cada poço, foi denominado nesta pesquisa como Perfil 01 e Perfil 02 equidistantes á $22.27 \mathrm{~km}$ entre si. Os perfis sedimentares apresentam resisitividades e estruturas variadas, correspondentes ao contexto litológico (ver tabela 1 e 2 ), que serviram como base para elaboração dos modelos diretos, exibidos na figura 3 abaixo:
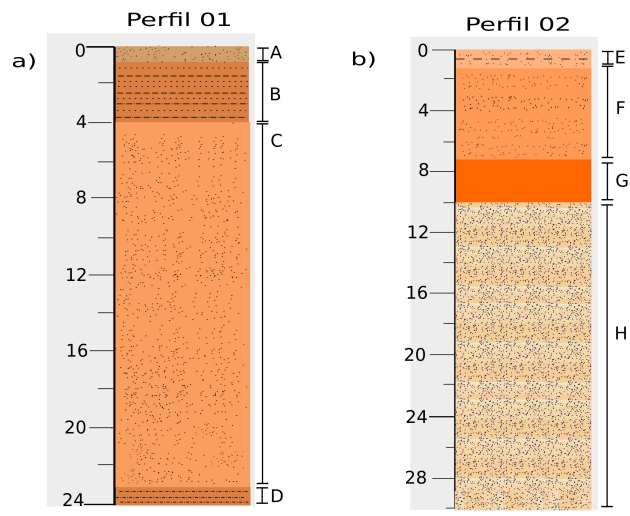

Figura 3: Perfil litológico adaptado dos dados disponibilizados da CPRM da a) Pousada do Mingote na vila de Alter de Chão nomeado como Perfil 01 b) Shopping Center Tapajós em Santarém nomeado como Perfil 02.

\begin{tabular}{|c|c|c|}
\hline \multicolumn{2}{|c|}{ Perfil 01 } \\
\hline Camadas & Espessuras & Litologia \\
\hline A & $0.4 m$ & areia argilosa amarelo avermelhado \\
\hline B & $3.6 m$ & areia argilosa branco amarronzado \\
\hline C & $19 m$ & areia média \\
\hline D & $01 \mathrm{~m}$ & argila \\
\hline
\end{tabular}

Tabela 1: Descrição do Perfil 01 baseados no perfil litológico da Pousada do Mingote na vila de Alter de Chão dispostos pelo site da CPRM.

\begin{tabular}{|c|c|c|}
\hline \multicolumn{2}{|c|}{ Perfil 02 } \\
\hline Camadas & Espessuras & Litologia \\
\hline $\mathrm{E}$ & $0.5 \mathrm{~m}$ & areno-argiloso amarelo avermelhado \\
\hline $\mathrm{F}$ & $6.5 \mathrm{~m}$ & areia argilosa amarela \\
\hline $\mathrm{G}$ & $3 \mathrm{~m}$ & argila plástica \\
\hline $\mathrm{H}$ & $20 \mathrm{~m}$ & areia fina amarelo avermelhado \\
\hline
\end{tabular}

Tabela 2: Descrição do Perfil 02 baseados no perfil litológico do Shopping Center Tapajós em Santarém dispostos pelo site da CPRM.

\section{Elaboração do modelo direto}

Segundo a tabela 1 mencionada acima, mostra-se as resistividades aparentes usada na produção dos modelos sintéticos. Essas variações foram baseados segundo site (2018), Silva and Filho (2009) e no site Infocontrol (2018), após a elaboração do perfil no software Matlab, modelouse três situações diferentes: período de estiagem, precipitação máxima e em presença de contaminantes. Para o Perfil 01, nota-se que as camadas que sofreram alterações nos períodos de estiagem e recarga máxima são as camadas $\mathbf{B}$ e $\mathbf{C}$, correspondentes a areia argilosa e areia média, e os câmbios de resistividade para as camadas A, B e C são atribuídos ao modelo em presença de contaminantes, assim mesmo, a última camada $\mathbf{D}$ do Perfil 01 não súfrio alteração na resistividade aparente por possuir uma litologia impermeável natural, verifica-se nas figuras 4,5 e 6.
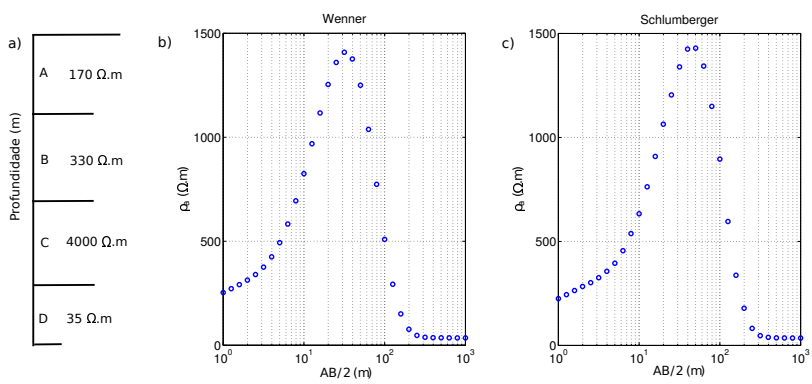

Figura 4: a) Perfil 01 geolétrico baseados nos dados de poços da CPRM na época de estiagem e as curvas de resisistividades para o b) arranjo Wenner e o c) arranjo Schlumberger.
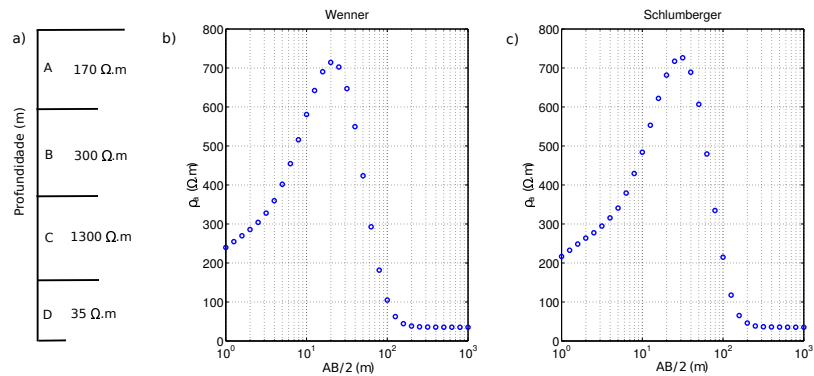

Figura 5: a) Perfil 01 geolétrico baseados nos dados de poços da CPRM na época de recarga máxima e as curvas de resisistividades para $\circ \mathrm{b}$ ) arranjo Wenner e o c) arranjo Schlumberger. 

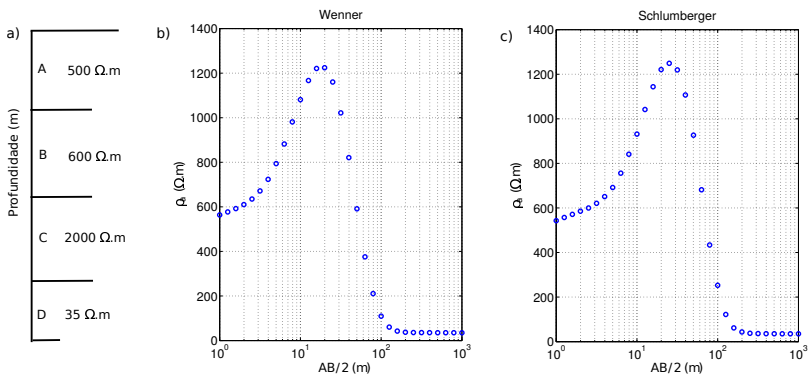

Figura 6: a) Perfil 01 geolétrico baseados nos dados de poços da CPRM sujeito a contaminantes e as curvas de resisistividades para o b) arranjo Wenner e o c) arranjo Schlumberger.

O Perfil 02, exibe uma variação na resistividade na camada $\mathbf{E}$ e $\mathbf{F}$, isto por causa da litológica que possui a área, nas camadas $\mathbf{G}$ e $\mathbf{H}$ não foram altamente afetadas, pois a argila plástica (camada $\mathbf{G}$ ) impede uma migração vertical tanto da água como de algum contaminante (ver figuras 7, 8 e 9). Observa-se que em ambos os perfis, as camadas com conteúdo de areia argilosa e areia média sofrem mudanças nas resistividades devido as caraterísticas físicas e quimicas dos fluidos (salinidade da água, contaminantes orgânicos e inorgânicos), assim como das caraterísticas do solo (porosidade, fluxo de água), pois estas influenciam na migração de fluídos tanto na horizontal como na vertical.
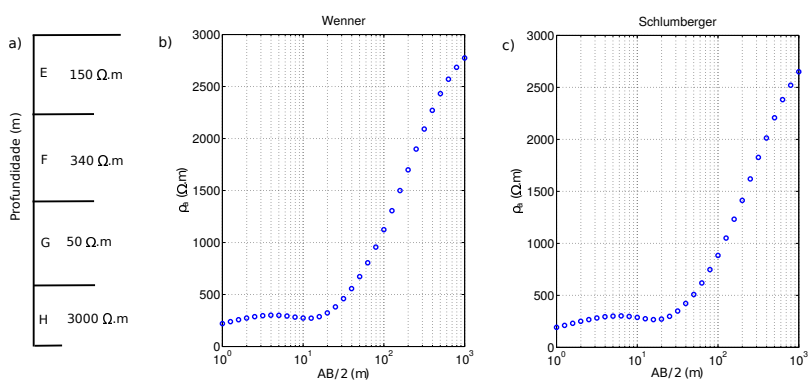

Figura 7: a) Modelo direto do Perfil 02 na época de estiagem e curvas de resisistividades para o b) arranjo Wenner e o c) arranjo Schlumberger.
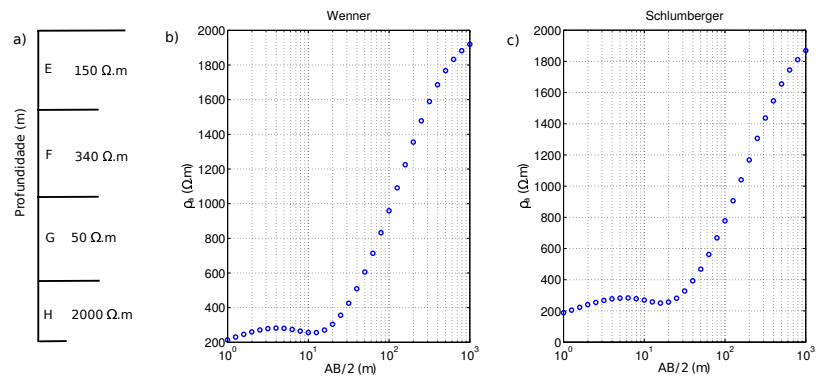

Figura 8: a) Modelo direto do Perfil 02 na época de recarga máxima e curvas de resisistividades para o b) arranjo Wenner e o c) arranjo Schlumberger.
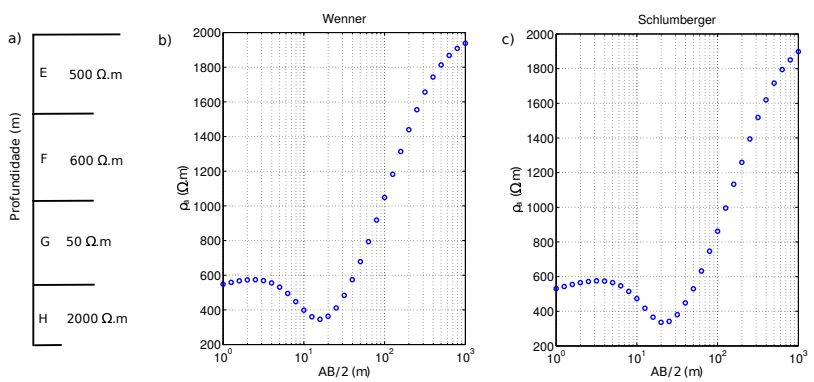

Figura 9: a) Modelo direto do Perfil 02 sujeito a contaminantes e curvas de resisistividades para 0 b) arranjo Wenner e o c) arranjo Schlumberger.

\section{Resultados}

Por meio da inversão, o programa calcula o fator geométrico $K$ para ambos os arranjos ajustando a curva dos dados estimados com as do modelo direto, obtendo os dados sintéticos 1D, constatados nas figuras 10 até 15 . Os resultados de inversão apresentam para as distintas situações acima, conferindo bons ajustes para o arranjo Schlumberger em comparação do Wenner (recuperouse respectivamente $92 \%$ e $72 \%$ em profundidade) em relação ao perfil litógico do modelo direto. Além disso, este arranjo apresenta desempenho computacional mais favorável, consequentemente menor número de iterações e baixo desgaste computacional. Mediante os dados obtidos, observamos que o arranjo escolhido Schlumberger, foi considerado o mais adequado para identificação de estruturas sub-verticais, como se constata no exemplo da tabela 3 e 4, dos resultados de inversão para a época de estiagem do perfil 01 e 02.

\begin{tabular}{|c|c|c|c|}
\hline \multicolumn{4}{|c|}{ Perfil 01 - Epóca de estiagem } \\
\hline Camadas & Modelo direto & $\begin{array}{c}\text { Inversão } \\
\text { Wenner }\end{array}$ & $\begin{array}{c}\text { Inversão } \\
\text { Schlumberger }\end{array}$ \\
\hline A & $0.4 \mathrm{~m}$ & $0.01374 \mathrm{~m}$ & $0.3999 \mathrm{~m}$ \\
\hline $\mathrm{B}$ & $3.6 \mathrm{~m}$ & $3.6731 \mathrm{~m}$ & $3.6001 \mathrm{~m}$ \\
\hline $\mathrm{C}$ & $19 \mathrm{~m}$ & $19.6315 \mathrm{~m}$ & $19.0001 \mathrm{~m}$ \\
\hline $\mathrm{D}$ & $01 \mathrm{~m}$ & - & \\
\hline
\end{tabular}

Tabela 3: Comparação dos dados do modelo direto com a inversão para os arranjos Wenner e Schlumberger.

\begin{tabular}{|c|c|c|c|}
\hline \multicolumn{4}{|c|}{ Perfil 02 - Epóca de estiagem } \\
\hline Camadas & Modelo direto & $\begin{array}{c}\text { Inversão } \\
\text { Wenner }\end{array}$ & $\begin{array}{c}\text { Inversão } \\
\text { Schlumberger }\end{array}$ \\
\hline $\mathrm{E}$ & $0.5 \mathrm{~m}$ & $0.5013 \mathrm{~m}$ & $0.5002 \mathrm{~m}$ \\
\hline $\mathrm{F}$ & $6.5 \mathrm{~m}$ & $6.4652 \mathrm{~m}$ & $6.4869 \mathrm{~m}$ \\
\hline $\mathrm{G}$ & $3 \mathrm{~m}$ & $3.2972 \mathrm{~m}$ & $3.1190 \mathrm{~m}$ \\
\hline $\mathrm{H}$ & $20 \mathrm{~m}$ & & \\
\hline
\end{tabular}

Tabela 4: Comparação dos dados do modelo direto com a inversão para os arranjos Wenner e Schlumberger.

Nota-se nas tabelas 3 e 4 os valores mais próximos ao modelo direto é o arranjo Schlumberger.

Inicialmente, foram gerados resultados de inversão para 
os modelos de estiagem e precipitação máxima (ver figura 10, 11, 13 e 14). Para os modelos, mudaram-se as resistividades apenas das camadas mais superfícies, onde estima-se a localização do nível freático (entre $7 \mathrm{~m}$ á 15 m) (MELO JUNIOR (2012)), com a intenção de entender o comportamento das propriedades dos solos, modelouse tomando em consideração a última camada como o embasamento.

Em épocas de estiagem resultados de resistividades mais elevadas do que nos períodos de recarga máxima (ver figura 10 e 13), pois no aquífero o armazenamento de água nos espaços entre os grãos, altera a interconecção dos poros e o fluxo de fluídos. No período de recarga máxima quando acontece uma saturação, a água tende a transbordar, as espessuras das camadas tendem a diminuir alterando na composição mineralógica, e modificando o $\mathrm{PH}$ da água e consequentemente o nível freático tende a elevar-se.

O comportamento dos contaminantes está em função de suas caraterísticas físicas e químicas, no entanto, o solo cumprem uma função importante na migração dos fluídos. As diferenças nos padrões de resisitividades em áreas contaminadas estão associadas ao tipo de contaminante, seja estes orgânicos ou inorgânicos. Nesta pesquisa as faixas das resistividades oscilam entre 500 - 600 ohm.m, nas duas primeiras camadas em ambos perfis (ver figura 12 e 15).
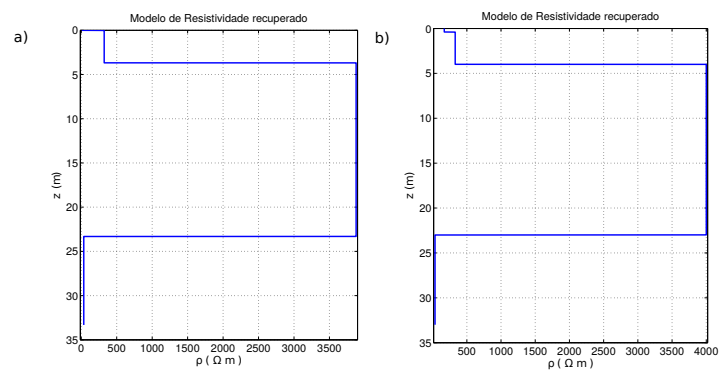

Figura 10: Inversão 1D do Perfil 01 na época de estiagem e curvas de resistividade para a) arranjo Wenner e b) arranjo Schlumberger.
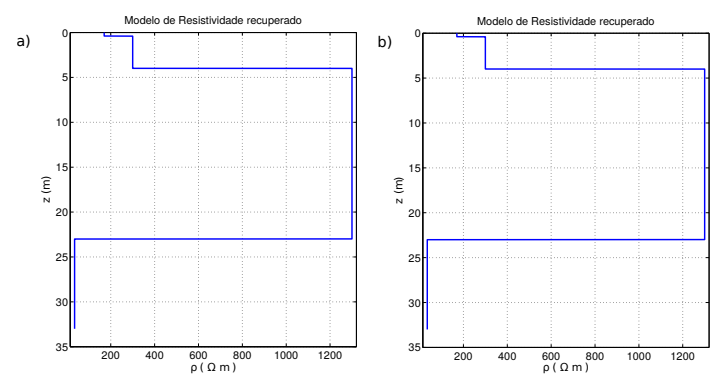

Figura 11: Inversão 1D do Perfil 01 na época de recarga máxima e curvas de resistividades para a) arranjo Wenner e b) arranjo Schlumberger.
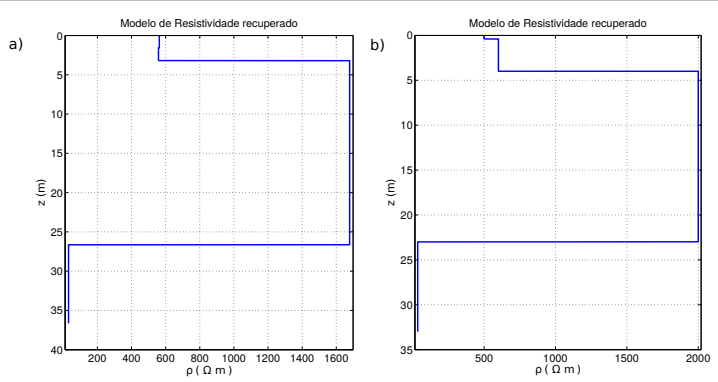

Figura 12: Inversão 1D do Perfil 01 sujeito a contaminantes e curvas de resistividades para a) arranjo Wenner e b) arranjo Schlumberger.
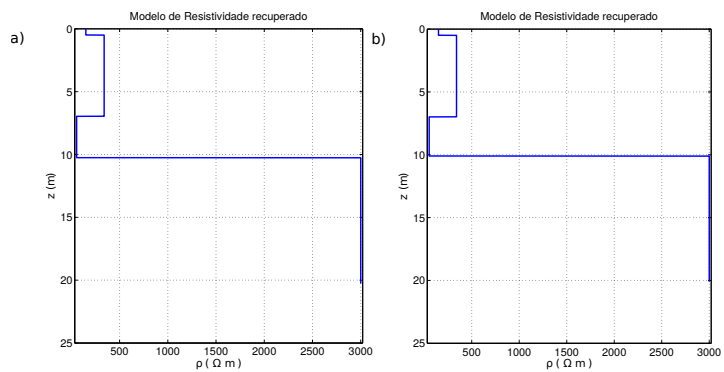

Figura 13: Inversão 1D do Perfil 02 na época de estiagem e curvas de resistividades para a) arranjo Wenner e b) arranjo Schlumberger.
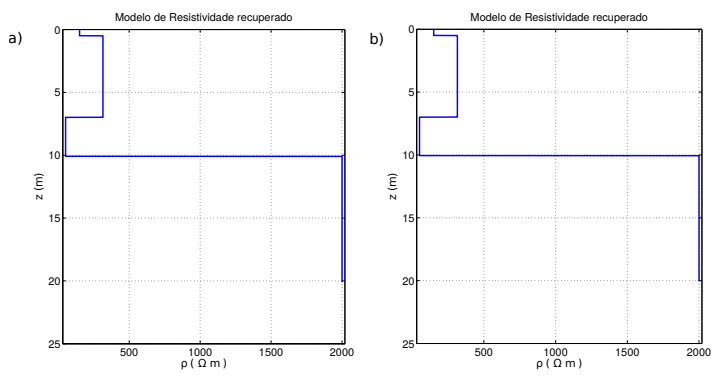

Figura 14: Inversão 1D do Perfil 02 na época de recarga máxima e curvas de resistividades para a) arranjo Wenner e b) arranjo Schlumberger.
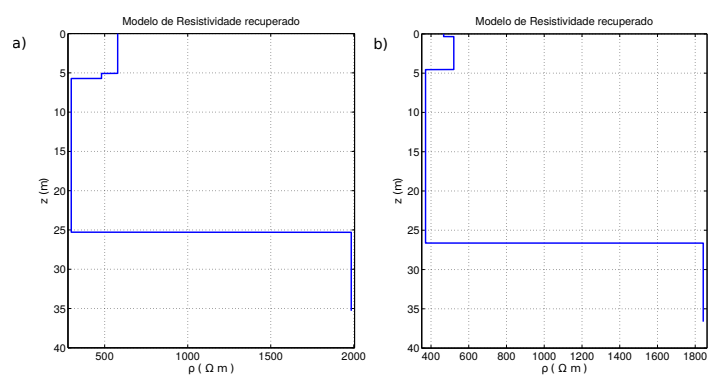

Figura 15: Inversão 1D do Perfil 02 sujeito a contaminantes e curvas de resistividades para a) arranjo Wenner e b) arranjo Schlumberger.

O tempo de residência dos contaminantes, faz com 
que altere a composição mineralógica do solo, criando condições para degração aeróbica e aneróbica, em decorrência desse processo há neoformações de minerais como hematita, ferro, goetita e magnetita e dependendo da fase do contaminante pode apresentrar altas resistividades Moreira et al. (2007) e Moreira and Braga (2009). Essas modificações ocorrem nas camadas mais superfíciais devido a dispersão, dissolução e mobilidade dos compostos. Segundo os resultados de inversão, observase que no Perfil 01 tem uma resposta geolétrica mais propensa a contaminação do que o Perfil 02, posto que a camada fina selante do Perfil 01, está a uma profundidade de aproximada $23 m$, enquanto que no Perfil 02 possui uma camada selante maior que a anterior e uma profundidade mais superfícial.

Nas figuras 16 e 17 mostra-se os modelos geolétricos construido a partir dos resultados de inversão para os três periodos de estudo.
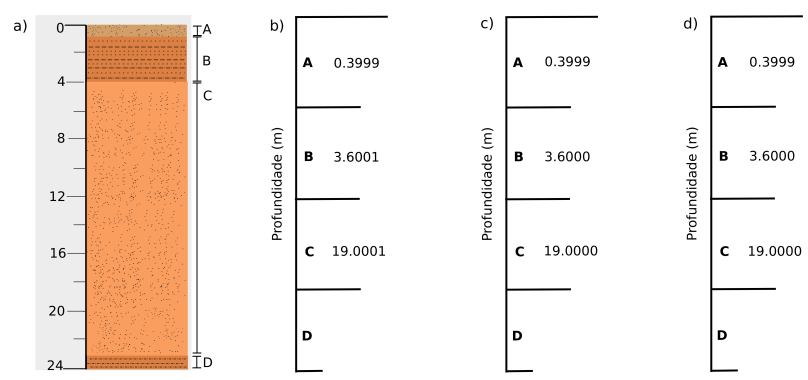

Figura 16: a) Modelo geológico do Perfil 01 para o arranjo Schlumberger b) modelo geolétrico no período de estiagem c)modelo geolétrico no período de estiagem d) sujeito a contaminantes.
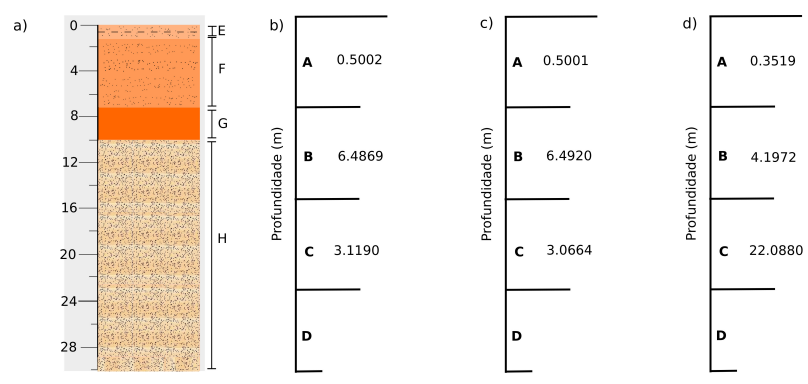

Figura 17: a) Modelo geológico do Perfil 02 para o arranjo Schlumberger b) modelo geolétrico no período de estiagem c) modelo geolétrico no período de estiagem d) sujeito a contaminantes.

\section{Conclusões}

Utilizando dados de inversão no método da SEV, neste trabalho teve-se como perspectiva a comparação computacional dos arranjos de Wenner e Shlumberger nos dados sintéticos 1D, elaborados a partir dos dados geológicos de dois poços (Poço Lobato e Rego LTDA e Poço Shopping Center), ambos adquiridos pelo site CPRM (2018).
Avaliou-se que o arranjo Schlumberger apresentou menor trabalho computacional e os resultados de inversão foram mais próximos dos modelos diretos para as três citações.

Tendo em vista os períodos estudados, as que apresentaram mais trabalho computacional foi as epócas de estiagem para ambos os arranjos, no entanto as aproximações conseguiram recuperar $99 \%$ dos dados originais. Para as épocas de recarga máxima as resisitividades recuperadas, foram obtidas com menor tempo.

De maneira geral os aquíferos porosos permeável permitem a dispersão e diluição dos contaminantes Perfil 01, assim como a oxigenação e criação de de condições para a degração aeróbica e anaeróbica, já o aquífero poroso e pouco permeável (Perfil 02), a mobilidade dos compostos é comprometida e a diluição e dispersão dos contaminantes é demorada, criando uma degração somente nas bordas dos contaminantes. Avaliando a migração vertical dos contaminantes, considera-se que o Perfil 01 é mais vulnerável do que o Perfil 02 como constados nos resultados acima. Conhecendo as limitações do método é necessário avaliar a migração horizontal e o fluxo hidrodinâmico do contaminante, a partir de métodos geofisicos como: Caminhamento Elétrico(CE), Polarização Induzida(PI), Radar de penetração no solo (GPR), EM induction.

Por fim, os dados coletados, processados permitem a elaboração dos perfis geolétrico, de resistidade auxiliando a geologia na preparação de áreas de monitoramento e/ou gerenciamento de áreas contaminadas.

\section{Referências}

ABREU, F. A. M. de; CAVAlCANTE, I. N. . D. A. A. M. . C. M. V. . M. M. A. d. S. ., 2013, O sistema aquífero grande amazônia - saga: Um imenso potencial de Água subterrânea no braisl.

Braga, A., 2016, Geofísica aplicada: Métodos geoelétricos em hidrogeologia.: Oficina de Textos.

CPRM, 2018, Companhia de pesquisa de recursos minerais: www.cprm.gov.br. (Acessado em: 10 Março, 2018).

Infocontrol, 2018, Redes de terras - resistividade do solo: http://www.ncbi.nlm.nih.gov/dbEST/dbEST_summary.html. (Acessado em: 6 Abril, 2018).

MELO JUNIOR, H. R., 2012, Aquífero alter do chão no estado pará - bacia sedimentar do amazonas. http://www.cprm.gov.br/bibliotecavirtual/estantevirtual.

Moreira, C. A., W. F. Aquino, and J. C. Dourado, 2007, Aplicação de métodos eletromagnetico indutivo (EM) no monitoramento de contaminantes em subsuperfície: Revista Brasileira de Geofísica, 25, 413 - 420.

Moreira, C. A., and A. C. d. O. Braga, 2009, Aplicação de métodos geofísicos no monitoramento de área contaminada sob atenuação natural: Engenharia Sanitaria e Ambiental, 14, 257 - 264.

Orellana, E., 1972, Prospeccion geoelectrica en corriente continua .: Madrid.

Silva, R., and W. Filho, 2009, O emprego de métodos geofísicos na fase de investigação confirmatória em cemitérios contaminados: 14.

site, 2018, Aterramento elÉtrico de sistemas (programa): https://www.scribd.com/document/355623661/ATERRAMENTOELETRICO-1-2-3-pdf. (Acessado em: 30 Março, 2018). 